\title{
Alterations of Expression of the Cytoskeleton after Immortalization of Human Fibroblasts
}

\author{
Shigeru Kaneko' ${ }^{1,2, *}$, Yasuhiro Satoh ${ }^{1, * *}$, Kunio Ikemura ${ }^{2}$, Tetsumi Konishi ${ }^{1}$, Taro Ohji ${ }^{1}$, Yuji \\ Karasaki $^{1}$, Ken Higashi', and Sadao Gotoh ${ }^{1}$ \\ ${ }^{1}$ Department of Biochemistry, and ${ }^{2}$ Department of Oral Surgery, University of Occupational and Environmen- \\ tal Health, Kitakyushu City 807, Japan
}

Key Words: cytoskeleton/human fibroblast/senescence/immortalization

\begin{abstract}
Human diploid fibroblasts (HDF) have a limited in vitro lifespan of population doubling level (PDL) 50-70. The molecular mechanism underlying cellular senescence and immortalization is not thoroughly understood. It has been reported that the cytoskeleton has diverse functions and may have a role in growth regulation through association with other cellular components.

To shed light on the relationship between functions of the cytoskeleton and senescence or immortalization, we investigated the alterations in gene expression after immortalization and measured the amounts of mRNAs for talin, vinculin, $\alpha$-actinin, tropomyosin 1 (TM1), vimentin, lamin A and C, and $\alpha$-tubulin by slot blot and Northern blot analyses. We found that the mRNAs for vinculin and vimentin were reduced and the mRNA for lamin A was increased in immortalized cells.

We also studied the cytoskeletal protein levels and their intracellular distributions by Western blot analysis and immunostaining. Most of the proteins studied behaved in a way similar to the mRNAs through senescence and immortalization. Vinculin, tropomyosins and vimentin showed their altered distributions in immortalized cells.
\end{abstract}

Human diploid fibroblasts (HDF) have a limited in vitro lifespan of population doubling level (PDL) 5070. Only a very few cells can survive the crisis and be immortalized after transformation by SV40. HDF thus have been proposed as an in vitro model system for studying the ageing process (23).

The molecular mechanism underlying cellular senescence and immortalization is not thoroughly understood. To elucidate the mechanism, several different approaches have been tried. Cell fusion experiments reported from several laboratories support the ideas that cellular senescent phenotype is dominant over immortalization and that the ageing process is programmed (38, 49). Introduction experiments of single chromosomes into immortal cells with an appropriate combination of chromosome and cell type can induce senescence and

* To whom correspondence should be addressed.

** Present address: Chiyoda Mutual Life Insurance Company, Tokyo Medical Room, 2-19-18, Kamimeguro, Meguro-ku, Tokyo 153, Japan.

Abbreviations: DTAF, 5-([4,6-dichlorotriazin-2-yl]amino)-fluorescein; HDF, human diploid fibroblasts; IF, intermediate filaments; MEM, minimum essential medium; MT, microtubules; PBS, phosphate-buffered saline; PDL, population doubling level; SSC, sodium citrate-sodium chloride; TM, tropomyosin mortality in immortal cells $(24,50)$. These experiments further corroborate the programme theory of cellular senescence.

The physical end of eukaryotic chromosomes is called telomere and is comprised of simple repeat sequences of $5-15 \mathrm{~kb}$. The unit sequence of it is 5 -TTA GGG-3' in mammals and is highly conserved throughout evolution (4). Although DNA polymerase is incapable of the complete replication of linear DNA molecules, the specialized telomere structures and the ribonucleoprotein enzyme, telomerase, allow for the complete replication of chromosome ends (4). In agreement with this notion, telomerase activity has been detected in unicellular eukaryotes, the germ line cells and human cancer cells $(21,33)$. However, telomerase activity has not been detected in any normal cell or tissue (22). The length of telomeric DNA in human fibroblasts decreases progressively as a function of in vitro ageing (21). Olovnikov and others proposed the telomere hypothesis of cellular ageing, arguing that absence of telomerase and shortening of telomere due to incomplete DNA replication are the cause of cellular senescence $(21,37)$.

One would expect alterations of gene and gene expression on the basis of the "programme" theory of senescence. In an attempt to find out genes involved in the cel- 
lular ageing process, we recently looked for genes which were differentially expressed in senescent and immortalized cells. With the subtractive differential hybridization technique, we selected 13 candidate clones, 3 of which were sequenced (45). One of them was the cDNA for vimentin, an intermediate filament of the cytoskeleton (45). From the rest of the 10 clones, we further obtained $2 \mathrm{cDNA}$ clones of vimentin and some unknown genes (unpublished data). Other laboratories have identified fibronectin gene as a highly expressed gene in senescent cells $(27,34,44)$. Fibronectin is an extracellular protein which is involved in cell junctions and cell adhesion to the extracellular matrix. The elevated expression of the vimentin gene in senescent cells, together with reports from other laboratories on the higher expression of the fibronectin gene, made us interested in the regulation of the cellular cytoskeleton in transformed, senescent and immortalized cells. In addition, no one has, so far, reported on alterations of the gene expression of cytoskeletal proteins before and after immortalization of cells, which prompted us to perform the present study.

In the present communication, to investigate the alterations of gene expression in immortalized cells, we estimated the amounts of mRNAs for talin, vinculin, $\alpha$-actinin, tropomyosin 1 (TM1), vimentin, lamin A and C, and $\alpha$-tubulin by slot blot and Northern blot analyses. We found that the mRNAs for vinculin and vimentin were reduced and the mRNA for lamin A was increased in immortalized cells compared with those in senescent cells. The amounts of the mRNAs for $\beta$-actin and $\alpha$-tubulin did not significantly change through transformation, senescence and immortalization. We also studied protein levels and their intracellular distribution by Western blot analysis and immunostaining.

\section{MATERIALS AND METHODS}

Cells and cell culture. Normal human fibroblasts, YH-1 cells, were obtained and described elsewhere (52). Cell strain B-32 is an SV40-transformed derivative of YH-1 and shows characteristic phenotypes common to virally transformed cells. B-32 cells are $100 \% \mathrm{~T}$-antigen positive throughout their lifespan until they die out at PDL 130-140. B-32F is an immortalized cell line derived from B-32 cells and has been in culture in our laboratory over PDL 280. Cells were grown in Eagle's minimum essential medium (MEM) supplemented with $10 \%$ fetal calf serum (Gibco, Grand Island NY, USA) in a $10 \%$ $\mathrm{CO}_{2}, 90 \%$ air environment at $37^{\circ} \mathrm{C}$.

Preparation of $m R N A$. Total RNAs were extracted using the RNA Extraction Kit (Pharmacia LKB Biotechnology, Uppsala, Sweden) from YH-1 (PDL 18), B-32 (PDL 82 and PDL 130 ) and B-32F cells (PDL 260) when cell monolayers were about $95 \%$ confluent. Poly(A) ${ }^{+}$RNAs were purified from the total RNAs using the mRNA Purification Kit (Pharmacia
LKB Biotechnology, Uppsala, Sweden).

cDNAs and an oligonucleotide used as probes in slot and Northern blot analyses. The following cDNAs were used as probes: (a) a 1-kb murine talin cDNA obtained from A. BenZe'ev (Weizmann Institute of Science, Israel) which corresponds to the $\mathrm{COOH}$-terminal 322 amino acids of murine talin (42), (b) a 2.8-kb chicken vinculin cDNA obtained from A. Ben-Ze'ev which contains the $5^{\prime}$ GC-rich region followed by the initiation ATG codon and about $2.6 \mathrm{~kb}$ coding sequence $(2,42)$, (c) a 3.1-kb human $\alpha$-actinin cDNA obtained from D.J. Kwiatkowski (Harvard Medical School, Boston) which contains $5^{\prime}$ untranslated sequence, followed by a long openreading frame extending to the stop codon, and the $3^{\prime}$ untranslated sequence containing four polyadenylation signal sequences (AATAAA) (53), (d) a 1.1-kb human TM1 cDNA obtained from G.L. Prasad (National Cancer Institute, Bethes$\mathrm{da}, \mathrm{MD}$ ) which contains the entire coding region, and $5^{\prime}$ and $3^{\prime}$ untranslated sequences $(39,40)$, (e) a 1.5 -kb human vimentin cDNA obtained from B. Honoré (Aarhus University, Aarhus C, Denmark) which covers the complete coding region of the vimentin gene (25), (f) a 2.4-kb murine lamin A cDNA obtained from N. Nakajima (Hokkaido University, Sapporo, Japan) which contains the C-terminal two-thirds of the lamin A-coding sequence and the $3^{\prime}$ untranslated sequence (35), (g) a $\beta$-actin cDNA was previously reported elsewhere (26).

The ${ }^{32} \mathrm{P}$-labeled cDNA probes were prepared by the nick translation method as previously reported elsewhere (45). As the probe for the human $\alpha$-tubulin mRNA, we used a synthetic single-stranded oligonucleotide of 40 bases which is of antisense orientation and derived from the translated exon 2 of the $\mathrm{H} \alpha 44$ gene (8). This oligonucleotide (Cat \#ON224) was purchased from Oncogene Science (Uniondale, NY) and was labeled with $\left[\gamma^{-32} \mathrm{P}\right] \mathrm{ATP}$ by the $5^{\prime}$-end labeling procedure using T4 polynucleotide kinase (Code No. 2021A) (Takara Shuzo Co. Ltd., Kyoto, Japan).

RNA slot blot analysis. Poly(A) ${ }^{+}$RNA (300 $\mathrm{ng}$ or $600 \mathrm{ng}$ ) of each sample was applied to a nitrocellulose filter (Cat. No. $1053 \mathrm{MM}$ ) or a nylon membrane filter (Cat. No. 1466MD) using the Hybri-Slot System (Cat. No. 1052MM) (GIBCO BRL, Gaithersberg, MD). Hybridization with each ${ }^{32} \mathrm{P}-\mathrm{la}-$ beled cDNA probe was performed in $50 \%$ formamide, $4 \times$ SSC $(1 \times$ SSC: $150 \mathrm{mM} \mathrm{NaCl}, 15 \mathrm{mM}$ trisodium citrate, $\mathrm{pH}$ 7.0), $5 \times$ Denhardt's solution $(1 \times$ Denhardt's solution: $0.02 \mathrm{~g}$ or Ficoll, $0.02 \mathrm{~g}$ of polyvinylpyrrolidone, $0.02 \mathrm{~g}$ of bovine serum albumin, and $\mathrm{H}_{2} \mathrm{O}$ to $100 \mathrm{ml}$ ), $0.5 \%$ SDS, $200 \mu \mathrm{g} / \mathrm{ml}$ salmon sperm DNA at $42^{\circ} \mathrm{C}$ for $17 \mathrm{hrs}$. Blotted membrane filters were washed twice in each $0.1 \%$ SDS-containing buffer; $2 \times \mathrm{SSC}, 1 \times \mathrm{SSC}$ and $0.1 \times \mathrm{SSC}$ for $20 \mathrm{~min}$ at $68^{\circ} \mathrm{C}$. Hybridization with $5^{\prime}$-end-labeled $\alpha$-tubulin oligonucleotide probe was performed in $6 \times \mathrm{SSC}, 2 \times$ Denhardt's solution, $0.1 \% \mathrm{SDS}, 200 \mu \mathrm{g} / \mathrm{ml}$ salmon sperm DNA at $42^{\circ} \mathrm{C}$ for $24 \mathrm{hrs}$ and the blotted filter was washed 4 times briefly in $4 \times$ SSC at room temperature, then in $2 \times \mathrm{SSC}$ at $65^{\circ} \mathrm{C}$ for $20 \mathrm{~min}$ and in $2 \times \mathrm{SSC}$ at room temperature for $5 \mathrm{~min}$.

These washed membrane filters were exposed to imaging 
plates, and the radioactive image was analyzed and quantitated with an image analyzer Fujix BAS 2000 model (Fuji Film Co. Ltd., Tokyo, Japan).

Northern blot analysis. Samples of poly(A) ${ }^{+}$RNA $(1.5$ $\mu \mathrm{g})$ were fractionated by electrophoresis on a $1.2 \%$ agarose gel containing formaldehyde and transferred to Hybond- $\mathrm{N}^{+}$ membrane (Amersham Japan Co. Ltd., Tokyo, Japan). Hybridization was performed as in the slot blot analysis. RNA size markers 0.24-9.5 kb (Cat. No. 15620-016) (GIBCO BRL, Gaithersberg, MD) were fractionated together with samples.

Antibodies. Primary antibodies used in Western blot analysis were: monoclonal mouse anti-vinculin $(1 / 1000$, BIOHIT, Helsinki, Finland), monoclonal anti-tropomyosin (1/1000, Chemical Credential ICN ImmunoBiologicals, Lisle, IL), monoclonal anti-vimentin (1/3000, DAKO, Kyoto, Japan) and anti- $\alpha$-tubulin (1/500, Cedarlane Labs. Ltd., Ontario, Canada). As the secondary antibody, we used anti-mouse Ig, peroxidase-linked species-specific whole antibody from sheep (code NA 931, Amersham Japan) which had been diluted $1 / 5000$ in PBS-T $(0.2 \%$ Tween 20 in PBS, a registered trademark of Atlas Chemical Industries Inc.) containing 1\% BSA.

For immunofluorescent staining, the same primary antibodies as in Western blot analysis were used, but they were all diluted $1 / 300$ in PBS-T containing 1\% BSA except the antibody to TM which was diluted $1 / 30$. Fluorescein-conjugated goat anti-mouse IgG (Jackson Immunoresearch Laboratories, Inc., West Grove, Pennsylvania) was used as the secondary antibody. DAKO X931 mouse IgG1 (DAKO, Kyoto, Japan) was used as the primary antibody for a negative control experiment of immunostaining.

Western blot analysis. For Western blot analysis, cells were washed three times in PBS and homogenized in $500 \mu \mathrm{l}$ of Laemmli buffer (28). After being boiled for $5 \mathrm{~min}$, the samples were drawn into a sterile hypodermic syringe and expelled through a 23-gauge needle. This shearing procedure was repeated three times. The samples were then loaded onto a $9 \%$ SDS acrylamide gel $(20 \mu \mathrm{g} /$ lane $)$ together with a size marker (Prestained SDS-PAGE standards, BIO-RAD, Hercules, CA). After electrophoresis, proteins were transferred to nitrocellulose membrane (Hybond ECL, Amersham) as described by Towbin et al. (51) in a semi-dry blotting apparatus (Biometra, Göttingen, FRG). Equal amounts of proteins in each lane were confirmed by the silver staining method (36) with Silver Stain II Kit Wako (Wako Pure Chemical Industries, Ltd., Osaka, Japan). The blotted membrane was washed in PBS-T and treated with 2\% BSA in PBS-T to block nonspecific binding. The blotted membrane was then treated with the primary antibodies appropriately diluted for each antibody. The membrane was washed three times in PBS and then treated with the secondary antibody, anti-mouse Ig, peroxidase-linked antibody. After the membrane was washed in PBS-T, antibodyreactive bands were visualized by chemiluminescent detection (ECL Western blotting detection kit; Amersham, Tokyo, Japan).

Immunofluorescent staining. Cells on glass slides (Matsu- nami Glass IND., LTD., Japan) were washed in PBS, fixed for $10 \mathrm{~min}$ with methanol at $-20^{\circ} \mathrm{C}$ and stored at $-80^{\circ} \mathrm{C}$ until use. The slides were incubated for 20 min with $2 \%$ goat serum (normal goat serum, DAKO) in PBS to block the nonspecific binding of the secondary antibody. The slides were washed in PBS and then incubated with one of the primary antibodies appropriately diluted in PBS containing 1.0\% BSA. After another wash, the slides were incubated with fluorescein (DTAF)-conjugated goat anti-mouse IgG (Jackson Immunoresearch Laboratories, Inc., West Grove, PA) for $60 \mathrm{~min}$ at room temperature before being washed three times. The slides were then mounted with coverslips and photographed at $\times 400$ magnification. As controls, slides were stained with a mouse monoclonal IgG1 antibody (DAKO X931) as the primary antibody and showed no significant fluorescence.

\section{RESULTS AND DISCUSSION}

In the present study, we used the quadruplets of cells: YH-1, young B-32, old B-32 and B-32F cells. All these cells were derived from the same parental diploid human fibroblast, YH-1 cells. By using these quadruplets, we can exclude the possible effects contributed by the difference of cell lineage on differential gene expressions.

Poly(A) ${ }^{+}$RNAs were extracted from YH-1, young B32 , old B-32 and B-32F cells, and the amounts of the mRNAs for talin, vinculin, $\alpha$-actinin, TM1, vimentin, lamin $\mathrm{A}$ and $\mathrm{C}$, and $\alpha$-tubulin were estimated by slot blotting (Fig. 1) and by Northern blotting (Fig. 2). Because the amount of the $\alpha$-tubulin mRNA was estimated to be equal in each cell strain of quadruplets by slot blotting, the $\alpha$-tubulin mRNA was not further analyzed by Northern blotting. We detected a single band by Northern analysis for each of the cytoskeletal mRNAs. The length of each mRNA for talin, vinculin, $\alpha$-actinin, TM1, vimentin, lamin A and lamin $\mathrm{C}$ were $9.0 \mathrm{~kb}, 6.0 \mathrm{~kb}, 4.0 \mathrm{~kb}, 1.1 \mathrm{~kb}, 1.9 \mathrm{~kb}, 3.0 \mathrm{~kb}$ and 1.9 $\mathrm{kb}$, respectively. The quantitative data from Fig. 2 were normalized with the radioactive intensity of the band corresponding to $\beta$-actin mRNA $(6,39,45,46)$. The quantitated and normalized data from Fig. 2 were illustrated in column graphs for the convenience of comparison (Fig. 3). All the blotting experiments were repeated 2 or 3 times and we show the representative results in figures (Figs. 1, 2 and 3).

We studied some of the cytoskeletal proteins on their protein levels and distributions by Western blot analysis and immunofluorescent staining. The availability of monoclonal antibodies to the cytoskeleton is limited, and so, in the present study, only a limited number of the cytoskeletal proteins was studied with available antibodies.

The cellular cytoskeleton is comprised of three kinds of filamentous systems; the microtubules (MT, $25 \mathrm{~nm}$ ), 
the microfilaments $(5 \mathrm{~nm})$ and the intermediate filaments (IF, $10 \mathrm{~nm}$ ) (1). Talin, vinculin and $\alpha$-actinin are microfilament-associated proteins and are involved in adhesion plaques and cell-cell contacts (1). TM1 is also a microfilament-associated protein which occurs along actin filaments (1).

Although talin, vinculin and $\alpha$-actinin are involved in formation of cell adhesion plaques, their expressions seem to be differentially regulated (16). In out present work, the expressions of talin and $\alpha$-actinin were reduced upon transformation by SV40, but they increased toward senescence and remained at the same level after immortalization (Fig. 3). On the other hand, the vinculin mRNA level was reduced on transformation by SV40, elevated toward senescence and again reduced after immortalization (Fig. 3). Our results and the earlier report (16) show that the regulations of both posi-
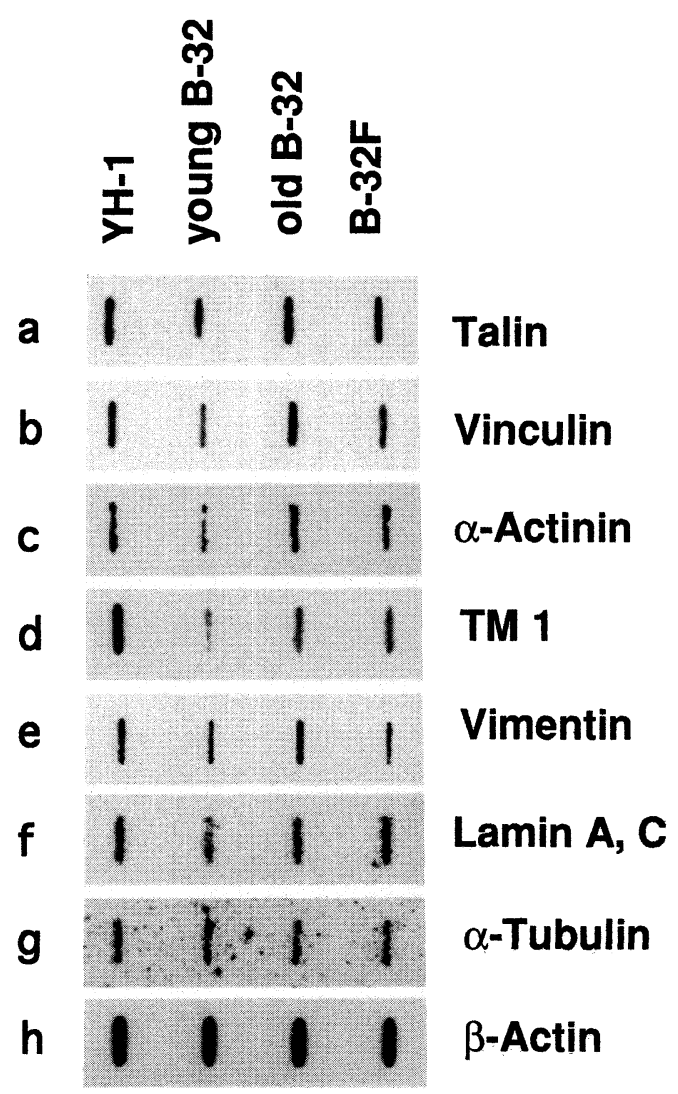

Fig. 1. Slot blot analysis of cytoskeletal mRNAs. Total RNAs were extracted from $\mathrm{YH}-1$, young B-32, old B-32 and B-32F cells. Poly(A) ${ }^{+}$RNAs were purified from each sample of the total RNAs and applied onto nitrocellulose membrane filters ( $300 \mathrm{ng} / \mathrm{slot}$ for $\beta$-actin and vimentin probes, and $600 \mathrm{ng} / \mathrm{slot}$ for other probes). The membrane filters were hybridized with ${ }^{32} \mathrm{P}$-labeled cDNA probes for talin (a), vinculin (b), $\alpha$-actinin (c), tropomyosin 1 (d), vimentin (e), lamin $A$ (f) and $\beta$-actin (h) as well as with ${ }^{32} \mathrm{P}$-labeled oligonucleotide probe for $\alpha$-tubulin (g). tive and negative modulations of gene expression are different between talin or $\alpha$-actinin and vinculin.

An earlier work reported no detectable vinculin mRNA in cancer cells (42). Transfection of vinculin cDNA into tumor cells brought about suppression of their tumorigenic ability (42). Suppression of vinculin expression by antisense transfection confers anchorage independent growth on 3T3 cells (43). The protein level of vinculin seems to be parallel with its mRNA level (Figs. 1, 2, 3 and 4). In our present study, we are inclined to emphasize the altered distribution of vinculin rather than the mRNA or protein levels. The cytoplasmic distribution of vinculin in immortalized cells is different from that in YH-1 cells (Fig. 5). In immortal B-32F cells, vinculin tends to be dense at the perinuclear locale and thinner toward the periphery of the cytoplasm in contrast to its rather homogeneous distribution in YH-1 cells (Fig. 5). Although we cannot at present elucidate the meaning of this finding, our present result as well as others $(42,43)$ are compatible with the idea that the reduced level and the altered distribution of vinculin may contribute to the immortal state of cells.

TMs, microfilament-associated proteins, are composed of 6 isoforms (39) and not directly involved in adhesion plaques and cell-cell contacts. The expression of
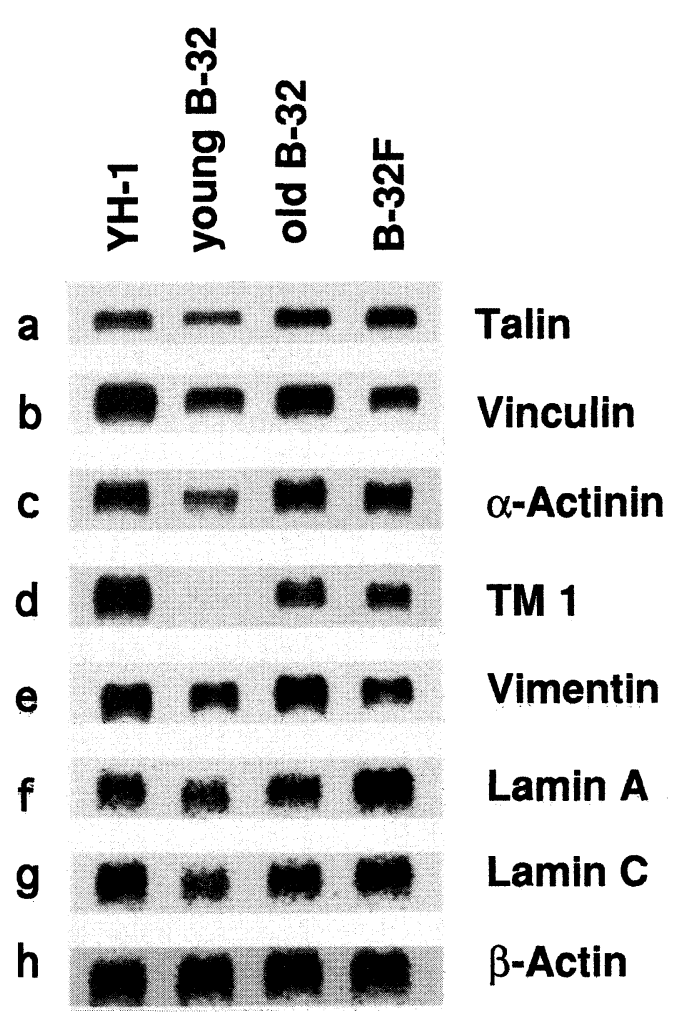

Fig. 2. Northern blot analysis of cytoskeletal mRNAs. Poly(A) ${ }^{+}$ RNA samples were electrophoresed and analyzed by Northern blotting with probes as in Fig. 1. 
TM1 has been reported to be much suppressed on transformation of mouse cells by the ras oncogene (40). Introduction of TM1 cDNA into ras-transformed 3T3 cells restored the normal phenotype such as anchorage dependent growth (40). Furthermore, Rastinejad et al. reported tumor suppression by RNA from the $3^{\prime}$ untranslated region of $\alpha$-tropomyosin (41). In our present study, TM1 expression is much depressed upon transformation and only a very faint band of the TM1 mRNA can be detected (Fig. 3). This result is compatible with earlier reports $(39,40,41)$. TM1 mRNA level increased toward senescence, but only to a level much lower compared with that of young YH-1 cells, and this low level remained the same after immortalization (Fig. 3). This pattern of expression of TM1 through transformation, senescence and immortalization is rather unique compared with those shown by the other cytoskeletal components (Fig. 3). The protein levels of TMs behave similarly as the TM1 mRNA level, but less drastically: they are reduced but still detectable in young B-32 cells (Fig. 4). In Fig. 4, b, only 3 bands of TMs can be distinguished because some of the TM isoforms are of very close molecular weights (39). The cytoplasmic distribu- tion of TMs in immortal B-32F cells is quite different from that in YH-1 cells. In YH-1 cells, TMs are homogeneously stained only in the cytoplasm and not associated with the nuclear membrane (Fig. 5). In B-32F cells, however, TMs occur in the nuclei and seem to be associated with the nuclear membrane because nuclei and nuclear margins are densely stained (Fig. 5). These observations indicate that TMs may be related with the cellular immortalization process.

Vimentin is a ubiquitous intermediate filament protein that plays a fundamental role in maintaining cell structure and integrity (29). Vimentin gene is a single copy gene and encodes mRNA of about $1.9 \mathrm{~kb}(10)$. Vimentin not only sustains cellular architecture but also suppresses transformed phenotype. The human cDNA for vimentin was able to revert chemically transformed baby hamster kidney cells (BHK) to an anchorage-dependent normal cellular phenotype (9). Normal lymphocytes express vimentin, but Burkitt's lymphoma cells do not (31). In our present study, vimentin expression was depressed upon transformation by SV40, and increased in senescent cells and again decreased after immortalization (Fig. 3). This result confirmed our earlier report a)

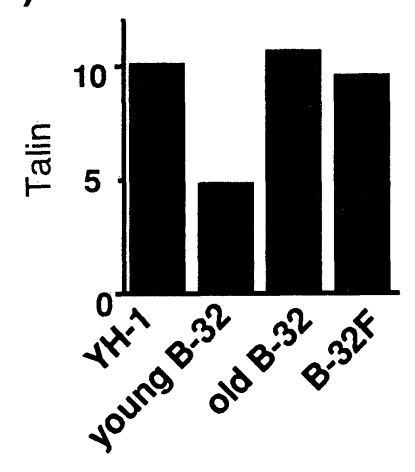

d)

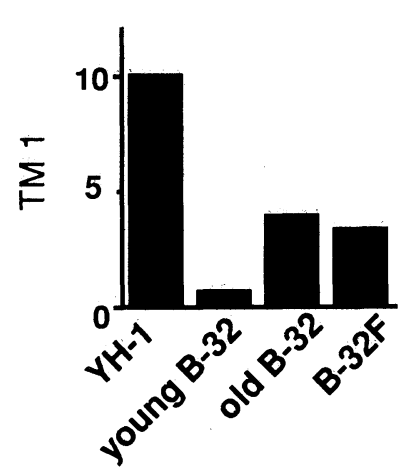

b)

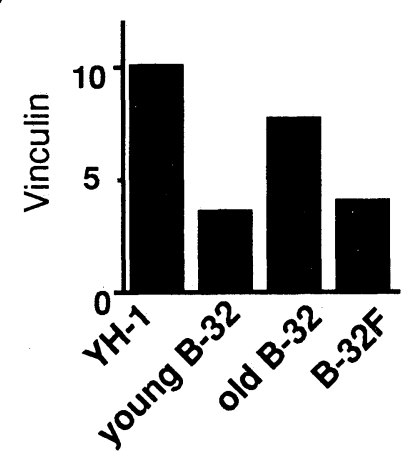

e)

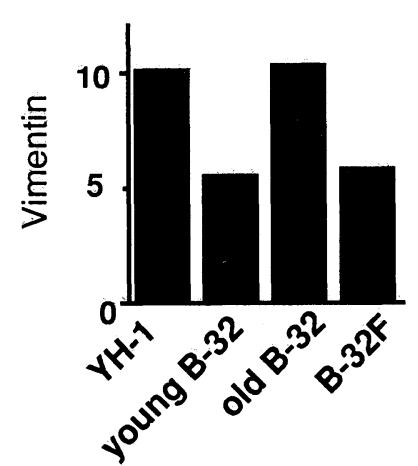

c)

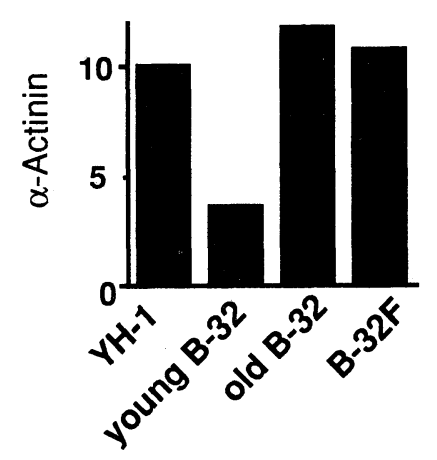

f)

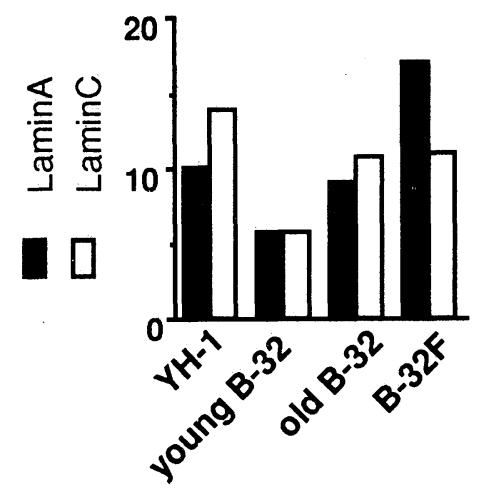

Fig. 3. Quantitative presentation of the alterations of the cytoskeletal mRNA levels. The data in Fig. 2 were quantitated and normalized by the radioactive intensities with $\beta$-actin probe. The ordinates stand for the comparative radioactive intensities in arbitrary units. 
(45). Lilienbaum et al. found that the abundance of vimentin mRNA is correlated with the quantity of vimentin present in the cells and they suggested that the level of vimentin is regulated by the abundance of mRNA (31). Figs. 4 and 5 verify that their suggestion is correct: the protein level of vimentin is correlated with its mRNA level (Figs. 3, 4 and 5). In the cytoplasm of B$32 \mathrm{~F}$ cells, vimentin was irregularly stained, showing fur shape in contrast to the homogeneous staining in $\mathrm{YH}-1$ cells (Fig. 5). The reduced amount and the altered distribution of vimentin may be related to the maintenance of immortality in B-32F cells.

The nuclear lamina is a fibrillar protein meshwork lining the inner surface of the nuclear envelope in eukaryotic cells (14). The major constituents of the nuclear lamina, intermediate filaments of the cytoskeleton, are lamins A, B and C (13). Lamins A and C interact specifically with mitotic chromosomes, and this lamin-chromatin interaction seems to be important for nuclear reassembly after mitosis $(5,15)$. In our present study, the lamin A mRNA decreased slightly upon transformation by SV40, increased in senescent cells and increased

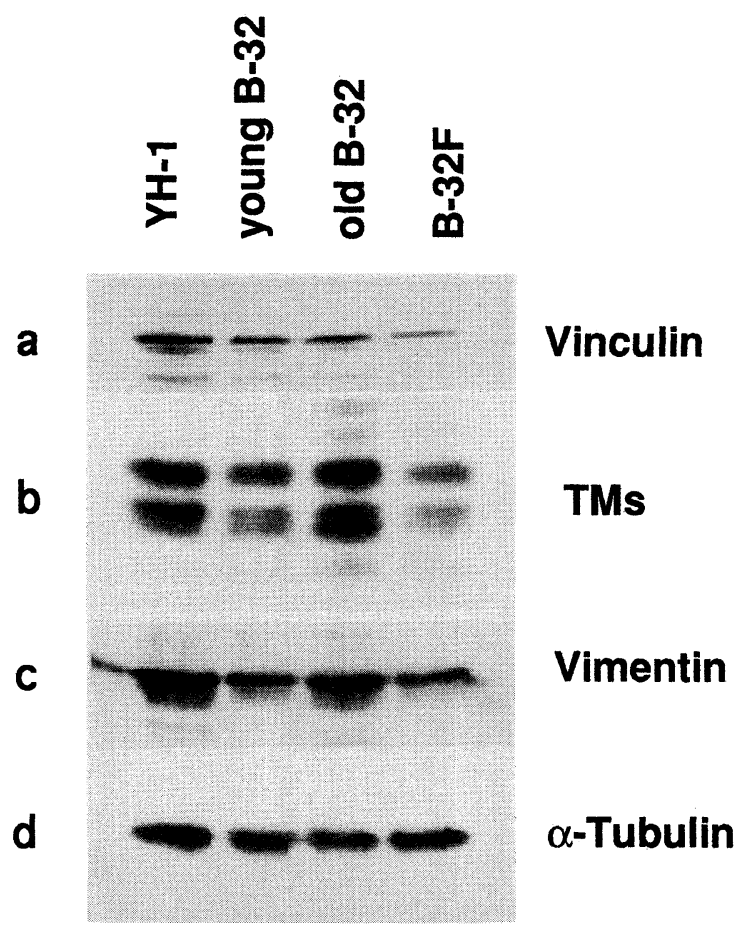

Fig. 4. Western blot analysis of cytoskeletal proteins. Equal amounts of total protein lysates extracted from YH-1, young B-32, old B-32 and B-32F cells were separated by electrophoresis and blotted onto nitrocellulose membrane filters ( $20 \mu \mathrm{g} /$ lane). The levels of vinculin (a), TM (b), vimentin (c) and $\alpha$-tubulin (d) were determined by quantitative immunoblotting with anti-vinculin, anti-TM, anti-vimentin and anti- $\alpha$-tubulin monoclonal antibodies followed by chemiluminescent detection with the anti-mouse IgG. much after immortalization (Fig. 3), while lamin $\mathrm{C}$ was not expressed as much as lamin A in B-32F cells (Fig. 3). This pattern of higher expression of lamin A in immortalized cells than in senescent cells is rather unique among mRNAs of cytoskeletal proteins so far studied. The lamins $A$ and $C$ mRNAs are produced from the same gene through differential splicing while lamin B is encoded by another unique gene $(11,32)$. Therefore, the differential behavior of the lamins $\mathrm{A}$ and $\mathrm{C}$ mRNAs may indicate that the regulation of alternative splicing is differentially modified in immortalized B-32F cells. Although the mechamism of the regulation of lamin A expression is unclear, the high expression of lamin A may be instrumental to the immortalization process.

The protein level of $\alpha$-tubulin remained almost the same throughout transformation, senescence and immortalization as did its mRNA, as shown in slot blot analysis (Figs. 1, 4 and 5). No alteration of its distribution was found by immunostaining after immortalization (Fig. 5).

The cytoskeleton performs a variety of functions such as the maintenance of the cellular scaffold, cellular motility and the transport of cytoplasmic organelles. To accomplish these tasks, the cytoskeletal components form a structural network (30). In addition, interactions of cytoskeletal components with other cellular constituents must have considerable significance in the growth regulation of cells. In particular, the association of the cytoskeleton with oncogene or anti-oncogene products and telomere is worth mentioning. Hamaguchi and Hanafusa reported that the association of $\mathrm{p} 60^{\mathrm{v}-\mathrm{src}}$ with cytoskeletal proteins is correlated with morphological transformation (19). This indicates that the cytoskeleton has a role in growth regulation other than just the maintenance of cellular scaffold.

Telomere seems to be related with the ageing process; that is, the older the cell, the shorter the telomere repeat sequence (20). After immortalization, the length of telomere becomes stabilized, probably by the reactivated enzyme telomerase (18). Shoeman et al. reported that vimentin and nuclear lamins A-C bind the synthetic oligonucleotides containing the telomere repeat sequence $(47,48)$. The earlier reports suggest that the telomeres of eukaryotic chromosomes occur in close proximity to the nuclear membrane and that they may be bound to nuclear lamina (3). Galcheva-Gargova and Dessev have shown nuclear lamina proteins and vimentin may be cross-linked to nuclear DNA (12). The ability of vimentin and nuclear lamins $\mathrm{A}-\mathrm{C}$ to interact with telomere sequences implies an active role for IF proteins in modulating chromosome function including telomere elongation as well as gene expression (12). Taken together, our present finding and earlier reports of others suggest that increased lamin A and reduced vimentin in immortal cells may modulate the regulation of the DNA 
replication, especially of telomeres, and therefore may have some potential significance in establishing immortality.

In this report, we studied only one set of parental and immortalized cells. To generalize our findings, we may have to analyze at least one more set of quadruplets. As for lamins $\mathrm{A}$ and $\mathrm{C}$, talin and $\alpha$-actinin, we measured only their mRNA levels, but not their quantities as of
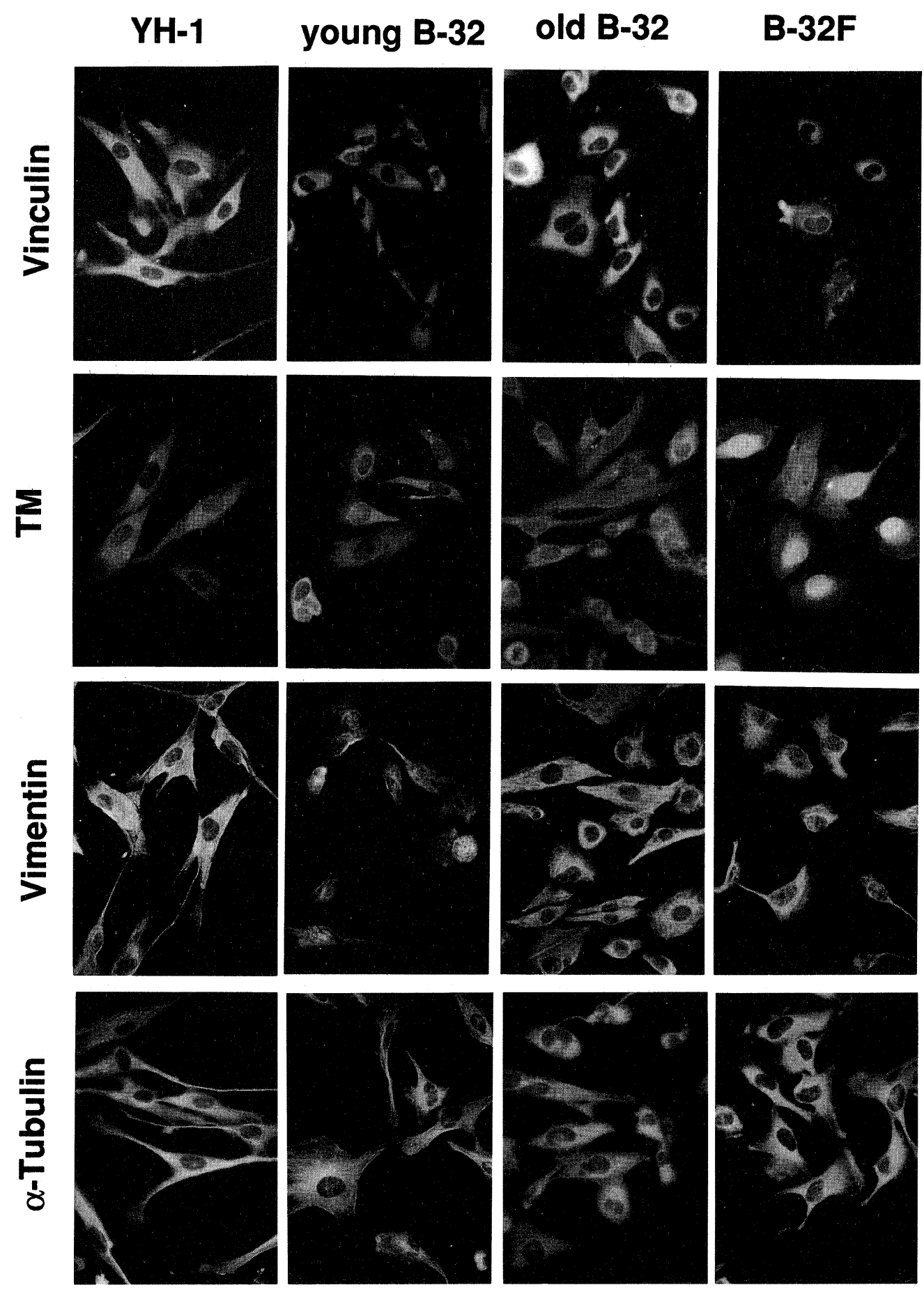

Fig. 5. Distribution of vinculin, TM, vimentin and $\alpha$-tubulin in YH-1, young B-32, old B-32 and B-32F cells $(\times 400)$. Cells grown on a glass slide were fixed with methanol and immunostained with an anti-vinculin, an anti-TM, an anti-vimentin or an anti- $\alpha$-tubulin monoclonal antibody followed by fluorescein (DTAF)-conjugated anti-mouse IgG. 
proteins. Some of the cytoskeletal components are, for their functions and assembly or disassembly, regulated through phosphorylation-dephosphorylation processes (7). Therefore, characterization of cytoskeletal proteins themselves including their phosphorylation and mutual interactions among themselves as well as associations with other cellular components in immortal cells remains to be studied in future.

Acknowledgments. We would like to express our appreciation to Prof. A. Ben-Ze'ev and Ms. U. Glück of Weizmann institute of Science for their valuable communication and sending us their talin and vinculin cDNA clones. We are also grateful to Dr. G.L. Prasad of National Cancer Institute for his helpful suggestions and providing us with his clone of TM1 cDNA. Special thanks are due to Drs. D.J. Kwiatkowski of Harvard Medical School, B. Honoré of Aarhus University and N. Nakajima of Hokkaido University for their generous gifts of the cDNAs for $\alpha$-actinin, vimentin and lamin A, respectively. We wish to acknowledge Drs. N. Nomoto and Y. Uezono of University of Occupational and Environmental Health for their valuable discussions and technical instructions.

This work was partially supported by a grant from University of Occupational and Environmental Health.

\section{REFERENCES}

1. Alberts, B., Bray, D., Lewis, J., RafF, M., Roberts, K., and Watson, J.D. 1994. Molecular Biology of the Cell, Garland Publishing, Inc., New York, pp.787-861.

2. Bendori, R., Salomon, D., and Geiger, B. 1987. Contactdependent regulation of vinculin expression in cultured fibroblasts: a study with vinculin-specific cDNA probes. Embo J., 6: 2897-2905.

3. BlackBuRn, E.H. 1984. The molecular structure of centromeres and telomeres. Annu. Rev. Biochem., 53: 163-194.

4. Blackburn, E.H. 1992. Telomerases. Annu. Rev. Biochem., 61: 113-129.

5. BURKE, B. 1990. On the cell-free association of lamins A and C with metaphase chromosomes. Exp. Cell Res., 186: 169-176.

6. Chen, K.Y., Chang, Z.F., Pang, J.H., He, G.S., and Liu, A.Y. 1989. Polyamine metabolism and cell-cycle-dependent gene expression in IMR-90 human diploid fibroblasts during senescence in culture. Exp. Gerontol., 24: 523-537.

7. Chou, Y.H., Rosevear, E., and Goldman, R.D. 1989. Phosphorylation and disassembly of intermediate filaments in mitotic cells. Proc. Natl. Acad. Sci. USA, 86: 1885-1889.

8. Dobner, P.R., Kislauskis, E., Wentworth, B.M., and Villa, K.L. 1987. Alternative $5^{\prime}$ exons either provide or deny an initiator methionine codon to the same alpha-tubulin coding region. Nucleic Acids Res., 15: 199-218.

9. Eiden, M.V., MacArthúr, L., and OKayama, H. 1991. Suppression of the chemically transformed phenotype of BHK cells by a human cDNA. Mol. Cell. Biol., 11: 5321-5329.

10. Ferrari, S., Battini, R., Kaczmarek, L., Rittling, S., Calabretta, B., De Riel, J.K., Philiponis, V., Wei, J.-F., and BASERGE, R. 1986. Coding sequence and growth regulation of the human vimentin gene. Mol. Cell. Biol., 6: 36143620.

11. Fisher, D.Z., Chaudhary, N., and Blobel, G. 1986. cDNA sequencing of nuclear lamins $\mathrm{A}$ and $\mathrm{C}$ reveals primary and secondary structural homology to intermediate filament proteins.
Proc. Natl. Acad. Sci. USA, 83: 6450-6454.

12. Galcheva-Gargova, Z. and Dessev, G.N. 1987. Crosslinking of DNA to nuclear lamina proteins by UV irradiation in vivo, J. Cell. Biochem., 34: 163-168.

13. Gerace, L. and Blobel, G. 1980. The nuclear envelope lamina is reversibly depolymerized during mitosis. Cell, 19: 277-287.

14. Gerace, L. and BuRKe, B. 1988. Functional organization of the nuclear envelope. Annu. Rev. Cell Biol., 4: 335-374.

15. Glass, J.R. and Gerace, L. 1990. Lamins A and C bind and assemble at the surface of mitotic chromosomes. J. Cell Biol., 111: $1047-1057$.

16. GlÜck, U., Rodríguez Fernández, J.L., Pankov, R., and BEN-ZE'EV, A. 1992. Regulation of adherens junction protein expression in growth-activated 3T3 cells and in regenerating liver. Exp. Cell Res., 202: 477-486.

17. GlÜCK, U., KwiatKowski, D.J.,. and Ben-Ze'ev, A. 1993. Suppression of tumorigenicity in simian virus 40-transformed 3T3 cells transfected with alpha-actinin cDNA. Proc. Natl. Acad. Sci. USA, 90: 383-387.

18. Greider, C.W. and BlaCKBURN, E.H. 1985. Identification of a specific telomere terminal transferase activity in Tetrahymena extracts. Cell, 43: 405-413.

19. Hamaguchi, M. and Hanafusa, H. 1987. Association of p60 $0^{\mathrm{src}}$ with Triton X-100-resistant cellular structure correlates with morphological transformation. Proc. Natl. Acad. Sci. USA, 84: 2312-2316.

20. Harley, C.B., Futcher, A.B., and Greider, C.W. 1990. Telomeres shorten during ageing of human fibroblasts. Nature, 345: $458-460$.

21. Harley, C.B. 1991. Telomere loss: mitotic clock or genetic time bomb? Mutat. Res., 256: 271-282.

22. Harley, C.B., Vaziri, H., Counter, C.M., and Allsopp, R.C. 1992. The telomere hypothesis of cellular ageing. Exp. Gerontol., 27: 375-382.

23. HaYflick, L. 1965. The limited in vitro lifetime of human diploid cell strains. Exp. Cell Res., 37: 614-636.

24. Hensler, P.J., Annab, L.A., Barrett, J.C., and PereiraSмIтн, O.M. 1994. A gene involved in control of human cellular senescence on human chromosome 1q. Mol. Cell. Biol., 14: 2291-2297.

25. Honoré, B., Madsen, P., Basse, B., Andersen, A., Walbum, E., Celis, J.E., and LefFers, H. 1990. Nucleotide sequence of cDNA covering the complete coding part of the human vimentin gene. Nucleic Acids Res., 18: 6692.

26. Катон, T., Ohmori, H., Múrakami, T., Karasaki, Y., Higashi, K., and Muramatsu, M. 1991. Induction of glutathione-S-transferase and heat-shock proteins in rat liver after ethylene oxide exposure. Biochem. Pharmacol., 42: 1247-1254.

27. Kumazaki, T., Robetorye, R.S., Robetorye, S.C., and Smith, J.R. 1991. Fibronectin expression increases during in vitro cellular sènešcence: correlation with increased cell area. Exp. Cell Rés., 195: 13-19.

28. LAEMMLI, U.K. 1970. Cleavage of structural proteins during the assembly of the head of the bacteriophage T4. Nature (London), 227: 680-685.

29. LAZARIDES, E. 1982. Intermediate filaments: a chemically heterogeneous, developmentally regulated class of proteins. Annu. Rev. Biochem., 51: 219-250.

30. Leung, M.F., Sokoloski, J.A., and Sartorelli, A.C. 1992. Changes in microtubules, microtubule-associated proteins, and intermediate filaments during the differentiation of HL-60 leukemia cells. Cancer Res., 52: 949-954.

31. Lilienbaum, A., Legagneux, V., Portier, M.M., Dellagi, K., 
and PAulin, D. 1986. Vimentin gene: expression in human lymphocytes and in Burkitt's lymphoma cells. Embo J., 5: 2809-2814.

32. MCKeon, F.D., Kirschner, M.W., and Caput, D. 1986. Homologies in both primary and secondary structure between nuclear envelope and intermediate filament proteins. Nature, 319: 463-468.

33. Morin, G.B. 1989. The human telomere terminal transferase enzyme is a ribonucleoprotein that synthesizes TTAGGG repeats. Cell, 59: 521-529.

34. Murano, S., Thweatt, R., Shmookler, R.R., Joners, R.A., Moerman, E.J., and Goldstein, S. 1991. Diverse gene sequences are overexpressed in Werner syndrome fibroblasts undergoing premature replicative senescence. Mol. Cell. Biol., 11: 3905-3914.

35. NaKajima, N. and Sado, T. 1993. Nucleotide sequence of a mouse lamin A cDNA and its deduced amino acid sequence. Biochim. Biophys. Acta, 1171: 311-314.

36. OAKLEY, B.R., KIRSCH, D.R., and MoRRIS, N.R. 1980. A simplified ultrasensitive silver stain for detecting proteins in polyacrylamide gels. Anal. Biochem., 105: 361-363.

37. Olovnikov, A.M. 1973. A theory of marginotomy. The incomplete copying of template margin in enzymic synthesis of polynucleotides and biological significance of the phenomenon. J. Theor. Biol., 41: 181-190.

37. Pereira-Smith, O.M. and Smith, J.R. 1988. Genetic analysis of indefinite division in human cells: identification of four complementation groups. Proc. Natl. Acad. Sci. USA, 85: 60426046.

39. Prasad, G.L., Meissner, S., Sheer, D.G., and Cooper, H.L. 1991. A cDNA encoding a muscle-type tropomyosin cloned from a human epithelial cell line: identity with human fibroblast tropomyosin TM1. Biochem. Biophys. Res. Commun., 177: 1068-1075.

40. Prasad, G.L., Fuldner, R.A., and Cooper, H.L. 1993. Expression of transduced tropomyosin $1 \mathrm{cDNA}$ suppresses neoplastic growth of cells transformed by the ras oncogene. Proc. Natl. Acad. Sci. USA, 90: 7039-7043.

41. Rastinejad, F., Conboy, M.J., Rando, T.A., and BlaU, H.M. 1993. Tumor suppression by RNA from the $3^{\prime}$ untranslated region of $\alpha$-tropomyosin. Cell, 75: 1107-1117.

42. Rodríguez Fernández, J.L., Geiger, B., Salomon, D., Sabanay, I., Zoller, M., and Ben-Ze'ev, A. 1992. Suppression of tumorigenicity in transformed cells after transfection with vinculin cDNA. J. Cell. Biol., 119: 427-438.
43. Rodríguez Fernández, J.L., Geiger, B., Salomon, D., and BEN-ZE'Ev, A. 1993. Suppression of vinculin expression by antisense transfection confers changes in cell morphology, motility, and anchorage-dependent growth of 3T3 cells. J. Cell. Biol., 122: 1285-1294.

44. RubelJ, I. and Pereira-Smith, O.M. 1994. SV40-transformed human cells in crisis exhibit changes that occur in normal cellular senescence. Exp. Cell Res., 211: 82-89.

45. Satoh, Y., Kashimura, M., Kaneko, S., Karasaki, Y., Higashi, K., and GotoH, S. 1994. Cloning of cDNAs with possible association with senescence and immortalization of human cells. Mutat. Res., 316: 25-36.

46. Seshadri, T. and CAmpisI, J. 1990. Repression of c-fos transcription and an altered genetic program in senescent human fibroblasts. Science, 247: 205-209.

47. Shoeman, R.L., Wadle, S., Scherbarth, A., and Traub, P. 1988. The binding in vitro of the intermediate filament protein vimentin to synthetic oligonucleotides containing telomere sequences. J. Biol. Chem., 263: 18744-18749.

48. Shomman, R.L. and Traub, P. 1990. The in vitro DNA-binding properties of purified nuclear lamin proteins and vimentin. J. Biol. Chem., 265: 9055-9061.

49. Stein, G.H. and YANISHEvsKY, R.M. 1979. Entry into S phase is inhibited in two immortal cell lines fused to senescent human diploid cells. Exp. Cell Res., 120: 155-165.

50. Sugawara, O., Oshimura, M., KoI, M., Annab, L.A., and BARRETT, J.C. 1990. Induction of cellular senescence in immortalized cells by human chromosome 1. Science, 247: 707710 .

51. Towbin, H., Staehelin, T., and Gordon, J. 1979. Electrophoretic transfer of proteins from polyacrylamide gels to nitrocellulose sheets: Procedure and some applications. Proc. Natl. Acad. Sci. USA, 76: 4350-4354.

52. Yanagisawa, K., Suenaga, Y., Nishio, K., and GotoH, S. 1983. Establishment of a human diploid cell strain. J. of University of Occupational and Environmental Health, 5: 49-54.

53. Youssoufian, H., McAfee, M., and KwiATKowski, D.J. 1990. Cloning and chromosomal localization of the human cytoskeletal $\alpha$-actinin gene reveals linkage to the $\beta$-spectrin gene. Am. J. Hum. Genet., 47: 62-71.

(Received for publication, November 15, 1994 and in revised form, December 28, 1994) 